ADVANCES IN SPANISH PHYSICAL

OCEANOGRAPHY

M. Espino, J. Font, J.L. Pelegrí,

A. Sánchez-Arcilla (eds.)
Scientia Marina 76S1

September 2012, 177-186, Barcelona (Spain)

ISSN: 0214-8358

doi: 10.3989/scimar.03615.19F

\title{
On the parameterization of the drag coefficient in mixed seas
}

\author{
HÉCTOR GARCÍA-NAVA ${ }^{1}$, FRANCISCO J. OCAMPO-TORRES ${ }^{2}$ \\ and PAUL A. HWANG ${ }^{3}$ \\ ${ }^{1}$ Instituto de Investigaciones Oceanológicas, Universidad Autónoma de Baja California, Km 103 Carretera \\ Tijuana-Ensenada, 22860, Ensenada, Baja, California, México. \\ ${ }^{2}$ Departamento de Oceanografía Física, Centro de Investigación Científica y de Educación Superior de Ensenada, \\ Ensenada, Baja, California, México. E-mail: ocampo@cicese.mx \\ ${ }^{3}$ Remote Sensing Division, Naval Research Laboratory, 4555 Overlook Avenue SW Washington DC.
}

\begin{abstract}
SUMMARY: An analysis of the performance of parameterizations for the drag coefficient $C_{D}$ over the ocean is presented. The results were obtained by considering detailed observations from the recent IntOA experiment in which a co-existence of wind sea and swell provides characteristic mixed sea conditions in a wide range of wind speeds. Recent research has advanced our understanding of air-sea fluxes, proposing new functional forms for the drag coefficient, as well as applying wavelength scaling and determining dimensionally consistent expressions for the drag coefficient. Nevertheless, a detailed analysis of the influence of wind sea parameters confirms the need to include the sea state dependence on parameterizing $C_{D}$ for mixed sea conditions. It is also shown that better results are obtained when aerodynamic roughness is considered as a function of wave age and wave steepness, or equivalently if $C_{D}$ is expressed as a function of a characteristic peak frequency defined through the wave momentum spectrum.
\end{abstract}

Keywords: drag coefficient, sea state, swell, mixed seas.

RESUMEN: EL COEFICIENTE DE ARRASTRE SOBRE LA SUPERFICIE DEL MAR COMO FUNCIÓN DE LAS CARACTERÍSTICAS DEL OLEAJE. Se presenta un análisis del desempeño de algunas parametrizaciones del coeficiente de arrastre $C_{D}$ sobre la superficie del mar. Los resultados se obtienen a partir de observaciones detalladas durante el experimento IntOA. En ese experimento la existencia simultánea de oleaje generado localmente y oleaje que proviene de tormentas lejanas, nos brinda características únicas del estado del mar con constituyentes mixtas de oleaje en una gama amplia de velocidades del viento. A través de investigaciones recientes se ha avanzado en el conocimiento de los flujos entre el océano y la atmósfera, al proponer nuevas formas funcionales del coeficiente de arrastre, así como al utilizar expresiones dimensionalmente consistentes que se basan en escalas asociadas a la longitud de onda de las olas. Los resultados de este trabajo confirman la necesidad de incluir la influencia del estado del mar en las parametrizaciones del coeficiente de arrastre, especialmente bajo condiciones mixtas de oleaje. También se demuestra que se obtienen mejores resultados cuando la escala de rugosidad aerodinámica se considera como una función de la edad de la ola y de la pendiente del oleaje local o de forma equivalente, cuando $C_{D}$ se expresa como función de una frecuencia característica asociada al pico espectral que se determina mediante el espectro del momento del oleaje.

Palabras clave: coeficiente de arrastre, estado del mar, swell, oleaje mixto.

\section{INTRODUCTION}

Air-sea fluxes are key boundary processes for both the atmosphere and the ocean. In particular, the wind stress drives the upper-ocean circulation, controls wave generation, and plays and important role in storm development and large-scale atmospheric circulation. An accurate estimate of wind stress is important for oceanic and atmospheric modelling, coupling and dynamic studies. By definition, the wind stress $\tau$ is given by the correlation of the wind turbulent fluctuations as 


$$
\tau=\rho\left(\overline{u^{\prime} w^{\prime}}, \overline{v^{\prime} w^{\prime}}\right),
$$

where $\rho$ is the air density, $\mathbf{u}^{\prime}=\left(u^{\prime}, v^{\prime}, w^{\prime}\right)$ is the wind turbulent velocity, and the overbar denotes the mean over a suitable period of time. Therefore, in order to compute wind stress directly, the wind turbulent velocity must be known. Measurements of turbulence over the ocean are a difficult and expensive task, so information of turbulent fluxes is scarce in both space and time. Instead, atmospheric and oceanic models must rely on flux parameterizations based on more readily measured variables. Typically, momentum transfer is estimated from the mean wind speed at a given height and a related drag coefficient $C_{D}$ with the so-called bulk aerodynamic formula

$$
|\tau|=\rho C_{D_{z}} U_{z}^{2}
$$

where $U_{z}$ is the wind speed at height $z$ and we have assumed that the wind stress has the same direction as the mean wind. The $C_{D}$ is a function of wind speed and measuring height, and it has been shown that it also depends on atmospheric stability and the sea state. The dependence on the measuring height and on atmospheric stability are overcome by using the wind speed at $10 \mathrm{~m}$ height in neutrally stratified atmospheric conditions. Somewhat surprisingly, after the stability correction, the most practical expressions of the drag coefficient seem to be in the form of dimensionally inconsistent polynomial functions of wind speed (e.g. Smith 1980, Large and Pond 1981, Yelland and Taylor 1996, Hwang et al. 2011).

It follows from the Monin-Obukhov similarity theory that the drag coefficient and the surface roughness length, $z_{0}$, are related as

$$
C_{D z N}=\kappa^{2} \ln ^{-2}\left(\frac{z}{z_{0}}\right),
$$

where $\kappa$ is the von Kármán constant and the subscript $N$ denotes neutral conditions. Hereinafter, the term drag coefficient will be used to refer to the neutral drag coefficient and the subscript $N$ will be omitted. In an aerodynamically rough flow, $z_{0}$ is expected to be related to the physical roughness of the sea surface, i.e. the waves. Consequently, a lot of effort has been devoted to parameterizing $C_{D_{10}}$ and $z_{0}$ in terms of wave parameters such as wave age (e.g. Donelan 1990, Drennan et al. 2003) and wave steepness (e.g. Taylor and Yelland 2001).

Recently, Foreman and Emeis (2010) proposed a new functional form to represent the drag coefficient for moderate to strong winds where no wind speed dependence was determined. While their results approximate rather well with data sets reported in the literature, the swell influence was not explicitly included in the analysis and the sea state conditions considered were wind sea-dominated. On the other hand, Hwang et al. (2011), applied wavelength scaling to propose a dimensionally consistent expression for the drag coef-

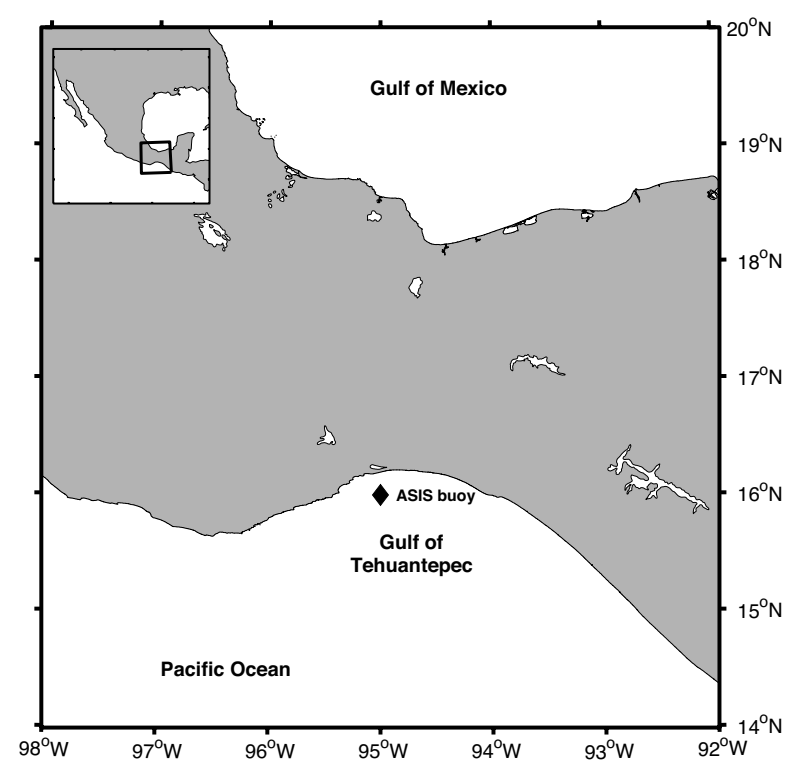

FIG. 1. - Map of the Gulf of Tehuantepec showing the mooring position of the ASIS buoy during the IntOA experiment.

ficient for both wind sea and mixed sea conditions. The swell effect is incorporated and the resulting drag coefficient is expressed as a function of a swell index and a proper dimensionless frequency.

Although extensive research has been conducted on the dependence of $C_{D}$ and $z_{0}$ on environmental parameters including wind speed, stability and surface waves (e.g. Geernaert 1999, Jones and Toba 2001), there are still some issues to deal with. Here we review the performance of some of the most popular and recent parameterizations of $C_{D}$ and $z_{0}$ in mixed seas using field data collected during the IntOA field campaign. Our attempt is to implicitly include the effect of swell on wind stress through the dependence of sea surface roughness on wind sea wave age and steepness. The results confirm the need to include the sea state dependence in parameterizing $C_{D}$ for mixed sea conditions. It is shown that better results are obtained when aerodynamic roughness is considered as a function of wind sea wave age and steepness or, as proposed by Hwang et al. (2011), if the $C_{D}$ is expressed as a function of a characteristic peak frequency defined through the wave momentum spectrum.

\section{THE GULF OF TEHUANTEPEC EXPERIMENT}

The Gulf of Tehuantepec is located in the Pacific Ocean on the southeast coast of Mexico (Fig. 1). This region is well-known for the occurrence of strong mountain gap winds known as Tehuanos (e.g. Romero et al. 2003). The Tehuano events are strong northerly winds that blow off the coast with speeds that can exceed $20 \mathrm{~m} \mathrm{~s}^{-1}$.

The Gulf of Tehuantepec air-sea interaction (IntOA) experiment took place from February 22 to April 4, 2005 in the Gulf of Tehuantepec. The goal of the 

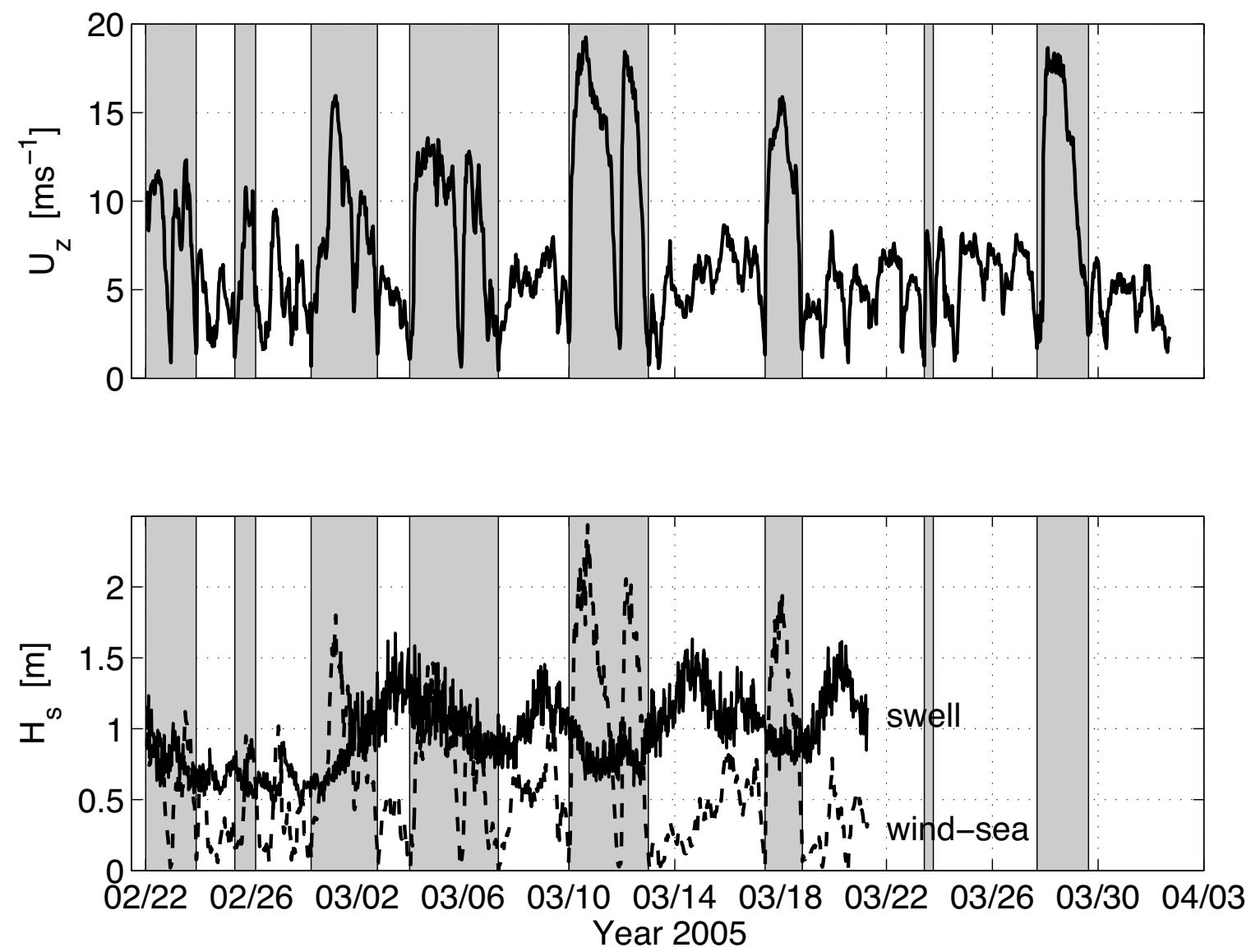

FIG. 2. - Time series of mean wind speed (top), significant wave height of swell (bottom, solid line), and wind sea (bottom, dashed line), as observed at the ASIS buoy during the IntOA experiment. Shaded areas denote the Tehuano events.

experiment was to investigate the impact of the strong offshore winds on air-sea interactions and surface waves.

All data used here were collected from an Air-Sea Interaction Spar (ASIS) buoy (Graber et al. 2000) moored in the central part of the Gulf of Tehuantepec about $22 \mathrm{~km}$ from the coast at a $60 \mathrm{~m}$ depth site (Fig. 1 ). Mean wind speed and turbulent fluctuations were measured with a sonic anemometer at $6.5 \mathrm{~m}$ from the surface. Waves were recorded with a pentagonal array of eight wave wires, one wire on each side of the pentagon and three wires at the centre, in which each wire measured the surface height at a single point. Wind velocity and surface height measurements were corrected for buoy motion as described by García-Nava et al. (2009). Wind speed was transformed to neutral values as

$$
U_{z N}=U_{z}+\frac{u_{*}}{\kappa} \psi_{u}\left(\frac{z}{L}\right),
$$

where $\psi_{u}$ is the dimensionless wind speed profile parameter proposed by Donelan (1990), $u_{*}=\sqrt{|\tau| / \rho}$ is the friction velocity, and $L$ is the Obukhov length scale. Then, wind speed at the standard 10-m height was computed by assuming a logarithmic wind profile

$$
U_{10 N}=U_{z N}+\frac{u_{*}}{\kappa} \ln \left(\frac{10}{z}\right) .
$$

Subsequently, the neutral drag coefficient was computed from (2) and the surface roughness length from (3).

An extensive description of the experiment can be found in the paper by Ocampo-Torres et al. (2011), while details on data acquisition and processing are given by García-Nava et al. (2009).

\section{Mean conditions}

Within the measuring period, eight Tehuano events were identified (shaded areas in Fig. 2). Each event lasted 1 to 3 days followed by an inter-Tehuano period of 2 to 7 days. Long-period swell, with a significant wave height of between 0.5 and $1.5 \mathrm{~m}$, reached the area continuously during the field campaign. The highest wind waves occurred during the strongest Tehuano winds, and the highest significant wave height was about $2.5 \mathrm{~m}$ at $20 \mathrm{~m} \mathrm{~s}^{-1}$ wind speed in association with fetch-limited growth (Fig. 2, see also Ocampo-Torres et al. (2011).

The persistence of swell induced the predominance of mixed sea conditions during the IntOA experiment. 


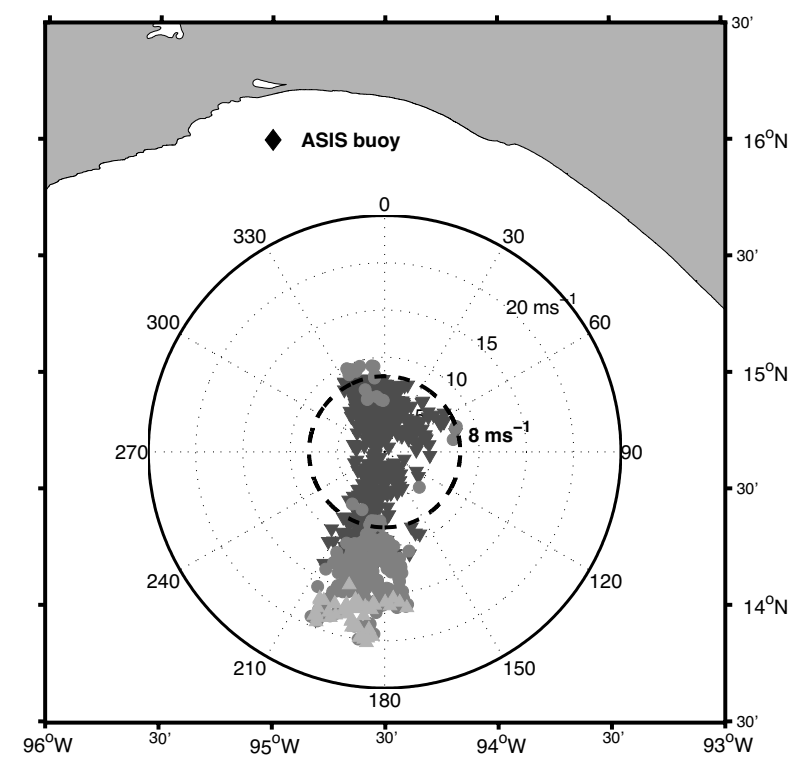

FIG. 3. - Polar representation of the wind speed observed at the ASIS buoy during the IntOA experiment. Concentric circles indicate wind speed and radial lines indicate the wind direction (oceanographic convention). The different symbols represent the sea state: swell-dominated conditions (down triangles), wind sea-dominated conditions (circles), and strongly wind sea-dominated conditions (up triangles)

Based on the energy contained in each part of the wave spectrum, data were classified as swell-dominated (SD) conditions when the energy of the swell, $E_{s}$, exceeded that of the wind sea, $E_{w s}$, and wind sea-dominated (WSD) conditions when $E_{w s}$ exceeded $E_{s}$. A subset of strongly wind sea-dominated (SWSD) conditions was established as $E_{w s}>5 E_{s}$. For reference, this criterion is commonly used to define "pure wind sea" conditions (e.g. Drennan et al. 2003, Drennan 2006), but the term "pure wind sea" is avoided here because it is known that swell occurred persistently in the data set (c.f. García-Nava 2009).

Figure 3 shows a polar representation of the wind velocity (i.e. joint distribution of magnitude and direction) observed during the field campaign. The wind velocity has two distinct conditions: during the Tehuano events the wind blows offshore (to the south) with a magnitude mostly between 8 and $20 \mathrm{~m} \mathrm{~s}^{-1}$; otherwise wind blows northward, rarely exceeding $8 \mathrm{~m} \mathrm{~s}^{-1}$. Most SD cases (down triangles) correspond to southerly winds (67\%), while WSD conditions (circles) correspond almost exclusively to northerly winds $(93 \%)$, i.e. to Tehuano events, and SWSD cases (up triangles) occurred only during the highest winds in association with the maximum significant wind sea heights (Fig. 2).

\section{DRAG COEFFICIENT}

The observed drag coefficient, $C_{D}$, displays two different behaviours as a function of wind speed: at low winds $\left(U<8 \mathrm{~m} \mathrm{~s}^{-1}\right)$ the $C_{D}$ decreases as wind speed in- creases and at high winds $\left(U \geq 8 \mathrm{~m} \mathrm{~s}^{-1}\right)$ the $C_{D}$ increases linearly with wind speed (Fig. 4).

The $C_{D}$ expected for open ocean conditions is represented in Figure 4 by the relationships of Smith (1980) and Large and Pond (1981) (dotted and dashed line, respectively; see also Table 1), which correspond to almost fully developed wind sea conditions (Drennan et al. 2003). As can be seen, the observed $C_{D}$ is higher than the open ocean estimates. In particular at low winds the observed $C_{D}$ is up to five times higher than the constant value proposed by Large and Pond (1981).

The differences between the observed $C_{D}$ and the open ocean estimates are caused by the strong influence of swell and by the presence of underdeveloped wind waves that occurred during the IntOA experiment. At low winds the direct interaction of swell with the air flow above causes the $C_{D}$ to increase (Pan et al. 2005, García-Nava et al. 2009). At high winds there are two other processes at play: the presence of underdeveloped, fetch-limited wind seas causes the surface roughness to increase (Drennan et al. 2003) and the presence of swell decreases the wind sea-associated roughness (García-Nava 2009). The overall result of these two processes is that the observed $C_{D}$ is higher than the open ocean estimates, corresponding to near fully developed conditions, but lower than the $C_{D}$ expected for underdeveloped wind seas in the absence of swell.

\section{Error assessment}

The error induced by motion correction on the computed $C_{D}$ was proved negligible during the IntOA experiment (see García-Nava et al. 2009, appendix A). In the following we consider the error induced by sampling variability on the $C_{D}$.

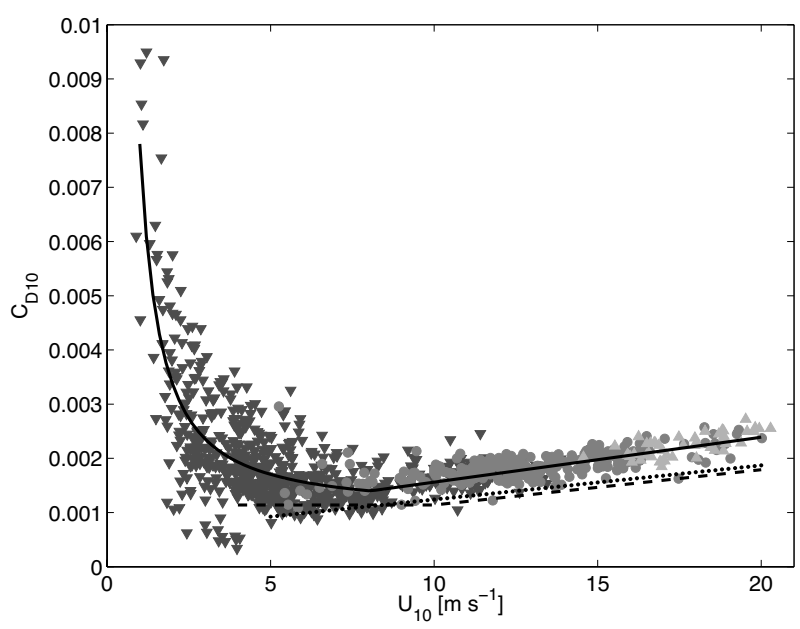

FIG. 4. - Drag coefficient as a function of wind speed for swell-dominated conditions (down triangles), wind sea-dominated conditions (circles), and the subset of strongly wind sea-dominated conditions (up triangles). Lines represent the best fit to this data set (solid), and the parameterizations of Smith (1980) (dashed) and Large and Pond (1981) (dotted). 
TABLE 1. - Parametric relationships for the drag coefficient and aerodynamic surface roughness used for comparison throughout this study.

\begin{tabular}{lccc}
\hline Reference & Variable & Parameterization & Range \\
\hline Large and Pond (1981) & $1000 C_{D}$ & 1.2 & $4<U_{10}<11 \mathrm{~m} \mathrm{~s}^{-1}$ \\
& & $0.49+0.065 U_{10}$ & $11<U_{10}<25 \mathrm{~m} \mathrm{~s}^{-1}$ \\
Smith (1980) & $1000 C_{D 10}$ & $0.61+0.063 U_{10}$ & $6<U_{10}<22 \mathrm{~m} \mathrm{~s}^{-1}$ \\
Foreman and Emeis (2010) & $C_{D_{10}}$ & $\left(C_{m}\left(U_{10}-U_{0}\right)+u_{*}\right)^{2} / U_{10}$ & $8<U_{10}<30 \mathrm{~m} \mathrm{~s}^{-1}$ \\
Drennan et al. (2003) & $z_{0} / H_{s_{w s}}$ & $3.35\left(u_{*} / C_{p_{w s}}\right)^{3.4}$ & $5<C_{p_{w s}} u_{*}<20$ \\
Taylor and Yelland (2001) & $z_{0} / H_{s}$ & $1200\left(H_{s} / \lambda_{p}\right)^{4.5}$ & $0.02<H_{s}^{s} / \lambda_{p}<0.06$ \\
Hwang et al. (2011) & $C_{D_{\lambda / 2}}$ & $\left.A_{c}\left(I_{s}\right) \omega_{*}\right)_{c}\left(I_{s}\right)$ & $0.01<\omega_{*}<0.2$ \\
\hline
\end{tabular}

The fractional sampling error, $\varepsilon$, for the mean covariance $\overrightarrow{u^{\prime} w^{\prime}}$ can be estimated (Donelan 1990) as:

$$
\varepsilon=\alpha_{u w}\left(\frac{z}{U \Omega}\right)^{\frac{1}{2}},
$$

where $U$ is the mean wind speed, $z$ is the anemometer height, $\Omega$ is the averaging time, and the coefficient $\alpha_{u w}=5.5$ (Sreenivasan et al. 1978). Propagation of the sampling error of the covariance through $C_{D}$ calculations yields

$$
\delta C_{D}=\frac{\delta \overline{u w}}{U^{2}}
$$

where $\delta C_{D}$ is the error on drag coefficient due to sampling variability, $\delta \overline{u w}=\varepsilon \overline{u^{\prime} w^{\prime}}$ is the sampling error on wind stress, and the sampling error on the mean wind speed was neglected.

As deduced from (6) and (7), the sampling error on $C_{D}$ is wind-dependent and decreases as the wind speed increases. For the IntOA experiment $(z=6.5 \mathrm{~m}$ and $\Omega=30 \mathrm{~min}$ ) the fractional sampling error on $C_{D}$ ranges between $7 \%$ and $19 \%\left(2 \mathrm{~m} \mathrm{~s}^{-1}<\mathrm{U}<20 \mathrm{~m} \mathrm{~s}^{-1}\right)$; the largest errors were computed for low wind conditions, and decreased to less than $15 \%$ for winds higher than $5 \mathrm{~m}$ $\mathrm{s}^{-1}$ and less than $10 \%$ for winds higher than $10 \mathrm{~m} \mathrm{~s}^{-1}$.

\section{Linear dependence on wind speed}

After the stability correction, most practical expressions for the $C_{D}$ are in the form of polynomial functions of wind speed. The most widely used parameterizations of the drag coefficient are probably in the form of a linear function of wind speed such as

$$
C_{D 10}=\left(a+b U_{10}\right) 10^{-3}
$$

where $a$ and $b$ are determined empirically by fitting observed data. Although this formula is widely used, especially for wind speeds in the range $7 \mathrm{~m} \mathrm{~s}^{-}$ ${ }^{1}<U_{10}<20 \mathrm{~m} \mathrm{~s}^{-1}$, there is no consensus on the value of $a$ and $b$ and there is a lot of scatter in the values proposed by various authors (see e.g. review in Table 1 of Guan and Xie 2004). At high winds, a linear increase in the observed $C_{D}$ with increasing wind speed is evident (Fig. 4), with the best fit (solid line) given by $a=0.73$ and $b=0.083$.
When a parameterization of the type of (8) is used to calculate $C_{D}$, an obvious problem is the selection of the coefficients $a$ and $b$. This selection will critically affect the accuracy of the results obtained through the parameterization; as an example, in Figure 5a it can be seen that the observed $C_{D}$ would be underestimated between $10 \%$ and $40 \%$ if the commonly used linear relationships of Smith (1980) is used to estimate $C_{D}$.

Based on dimensional arguments Charnock (1955) proposed

$$
z_{0}=\alpha u_{*}^{2} / g,
$$

where $\alpha$, the so-called Charnock parameter, was considered as a constant. A constant $\alpha$ implies that $C_{D}$ is exclusively a function of wind speed and measuring height. In accordance with Guan and Xie (2004), substituting (9) in (3) gives a nearly linear relation between $C_{D}$ and $U_{10}$ and the discrepancies observed in the values of $a$ and $b$ can be explained by the dependence of $\alpha$ on wave steepness. It is now generally accepted that $\alpha$ depends on wave parameters (see e.g. Komen et al. 1998, Jones and Toba 2001), even under hurricane conditions (Moon 2004). However, it is also believed that $\alpha$ remains constant for mature seas in certain conditions (Hara and Belcher 2004). The observed $C_{D}$ during the IntOA experiment can be well described by a constant $\alpha=0.023$ (García-Nava et al. 2009), as if it were from mature seas (Hara and Belcher 2004), although in high winds wind waves are underdeveloped and the wave age decreases as the wind speed increases.

Recently, Foreman and Emeis (2010) suggested that the wind speed dependence of $C_{D}$ is due to the neglect of a constant in the expected linear relation between $u_{*}$ and $U_{10}$ rather than to an increase in $z_{0}$ with the wind speed. They proposed a new definition of friction velocity as

$$
u_{*}=C_{m}\left(U-U_{0}\right)+u_{* 0}
$$

where $C_{m}=0.051$ is the newly defined drag coefficient (no longer wind speed-dependent), $u_{* 0}$ is the lower limit friction velocity for aerodynamically rough flow, and $U_{0}=U_{10}\left(u_{*}=u_{*}\right)$. From their analysis, Foreman and Emeis (2010) found $u_{*}=0.27 \mathrm{~m} \mathrm{~s}^{-1}$ and $U_{0}=8 \mathrm{~m} \mathrm{~s}^{-1}$.

It can be seen in Figure 6 that the observed friction velocity shows a linear dependence on wind speed for values greater than $7 \mathrm{~m} \mathrm{~s}^{-1}$, which coincides with 

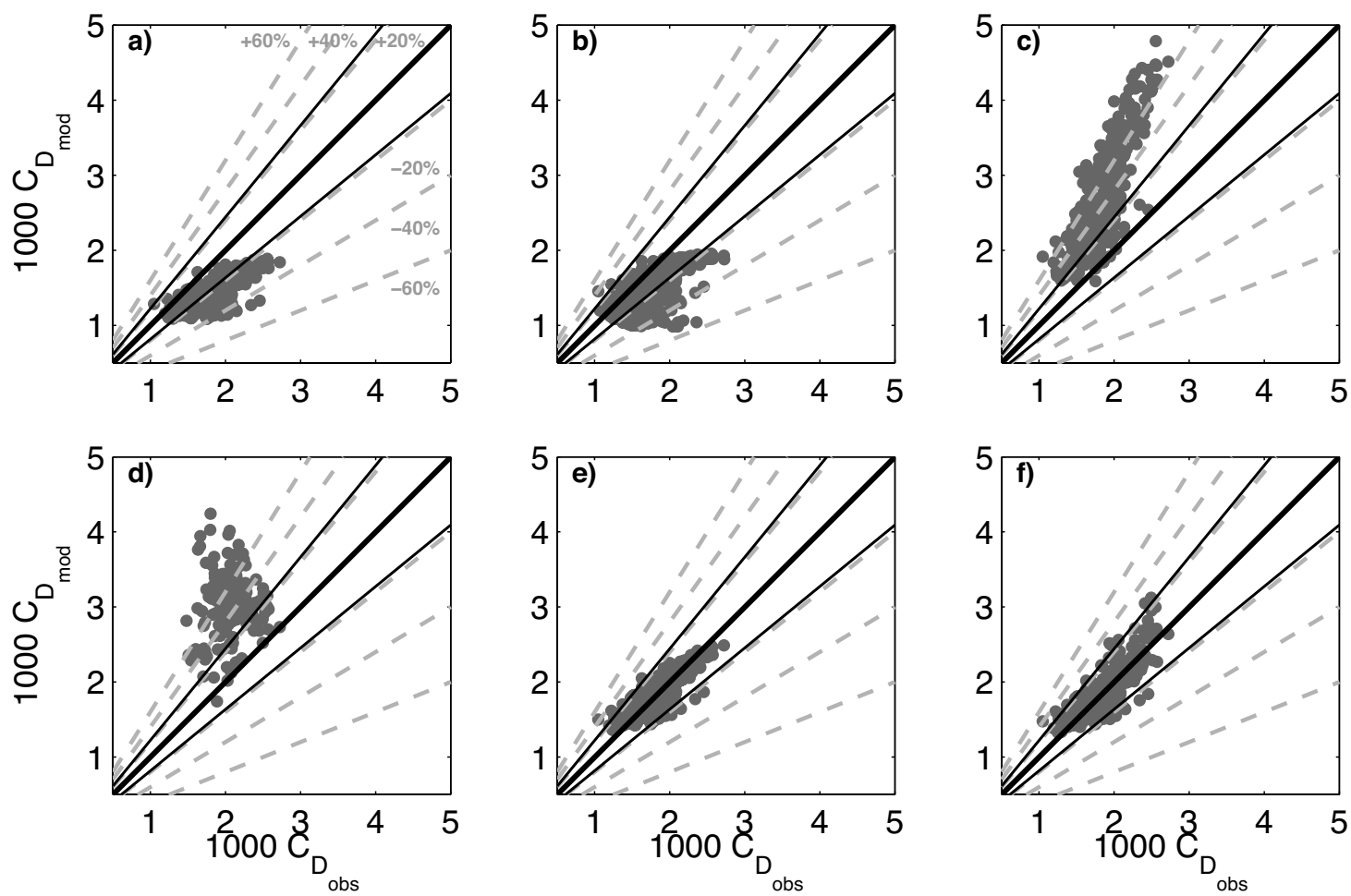

Fig. 5. - Comparison of the observed drag coefficient $\left(C_{D}\right)$ with the drag coefficient estimated $\left(C_{D_{m o n}}\right)$ using the relationships of: a) Smith (1980), b) Foreman and Emeis (2010), c) Drennan et al. (2003), d) Taylor and Yelland (2001), e) equation (13), and f) Hwang et al. (2011). The thick solid line is the 1:1 relationship, the dashed lines correspond to deviations from this relation, and the thin solid lines represent $90 \%$ confidence limits based on the sampling variability.

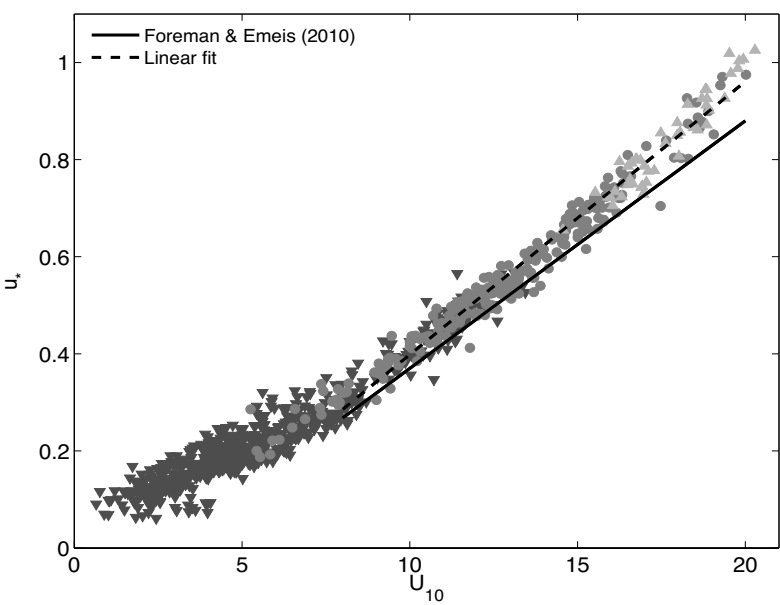

FIG. 6. - Friction velocity as a function of wind speed for swelldominated conditions (down triangles), wind sea-dominated conditions (circles), and the subset of strongly wind sea-dominated conditions (up triangles). Lines represent the linear fit (dashed), and the parameterizations of Foreman and Emeis (2010).

the expected $U_{0} \approx 7 \mathrm{~m} \mathrm{~s}^{-1}$ for the observed $\alpha=0.023$ (based on Figure 3 of Foreman and Emeis 2010). The observed values of $u_{*}$ are consistently higher than those estimated from the relationship of Foreman and Emeis (2010) (solid line), but within the range of values that they reported.

During the IntOA experiment the air flow could be regarded as aerodynamically rough most of the time even in low wind conditions (García-Nava et al. 2009). However, a linear regression of the observed $u_{*}$ against wind speed gives $u_{* 0}=0.24 \mathrm{~m} \mathrm{~s}^{-1}$ for $U_{0}=7 \mathrm{~m}$ $\mathrm{s}^{-1}$ and $u_{*}=0.29 \mathrm{~m} \mathrm{~s}^{-1}$ for $U_{0}=8 \mathrm{~m} \mathrm{~s}^{-1}$. Corresponding values of the newly defined drag coefficient (which correspond approximately to the square root of $C_{D}$ ) are $C_{m}=0.055$ and $C_{m}=0.056$, for $U_{0}=7 \mathrm{~m} \mathrm{~s}^{-1}$ and $U_{0}=8$ $\mathrm{m} \mathrm{s}^{-1}$, respectively. These values fall well within the range $C_{m}=0.051 \pm 0.006$ reported by Foreman and Emeis (2010).

Therefore, the IntOA data seems to support the hypothesis of Foreman and Emeis (2010). However, in terms of $C_{D}$ the parameterization of Foreman and Emeis (2010) with $C_{m}=0.051, U_{0}=8 \mathrm{~m} \mathrm{~s}^{-1}$ and $u_{* 0}=0.27$ $\mathrm{m} \mathrm{s}^{-1}$ (see Table 1) underestimates the observed $C_{D}$ by more than 20\% (Fig. 5b) and the correlation coefficient is reduced as compared with that obtained from a linear dependence of $C_{D}$ on wind speed (Table 2). By using the values of $C_{m}$ and $u_{* 0}$ computed from the IntOA experiment data, the error is reduced but the large scatter is always present and the correlation coefficient is the same.

\section{Sea state dependence in high winds}

A lot of effort has been devoted to express $C_{D}$ or equivalently $z_{0}$ as a function of wave parameters (e.g. Komen et al. 1998, Hwang 2004). In terms of wave age, defined here as the ratio between the phase speed $c_{p}$ and 
TABle 2. - Comparison of the estimates of the drag coefficient obtained with different parameterizations. $R$ is the correlation coefficient between the observed and estimated $C_{D}$, the fitting error $(\varepsilon)$ is computed as the norm of residuals divided by the square root of the number of data points, and $P_{90}$ indicates the percentage of data points within the $90 \%$ confidence bands based on the sampling variability of IntOA data.

\begin{tabular}{lccc}
\hline Parameterization & $R$ & $\varepsilon$ & $P_{90}[\%]$ \\
\hline Smith (1980) & 0.76 & $0.55 \times 10^{-3}$ & 30.5 \\
Foreman and Emeis (2010) & 0.73 & $0.33 \times 10^{-3}$ & 69.3 \\
Drennan et al. (2003) & 0.83 & $0.99 \times 10^{-3}$ & 14.0 \\
Taylor and Yelland (2001) & 0.06 & $1.05 \times 10^{-3}$ & 18.7 \\
Hwang et al. (2011) & 0.83 & $0.18 \times 10^{-3}$ & 95.3 \\
Equation (13) & 0.86 & $0.15 \times 10^{-3}$ & 96.8 \\
\hline
\end{tabular}

the friction velocity, surface roughness can be parameterized with a general form (Donelan 1990) such as

$$
z_{0} / H_{s_{w s}}=A_{1}\left(\frac{c_{p_{w s}}}{u_{*}}\right)^{B_{1}},
$$

Alternatively, Taylor and Yelland (2001) proposed a parameterization in terms of wave steepness as

$$
z_{0} / H_{s}=A_{2}\left(\frac{H_{s}}{\lambda_{p}}\right)^{B_{2}},
$$

where $H_{s}$ is the significant wave height, $c_{p}$ is the phase speed, $\lambda_{p}$ is the peak wave length, the suscript $w s$ indicates a wind sea property, and the constants $A_{i}$ and $B_{i}$ are to be determined empirically. Note that while wave age formula is based on wind sea properties, the parameterization of Taylor and Yelland (2001) uses the full spectrum properties in an attempt to include the effect of mixed seas.

It is believed that the direct interaction of swell with the air flow (see Donelan and Dobson 2001) has a great

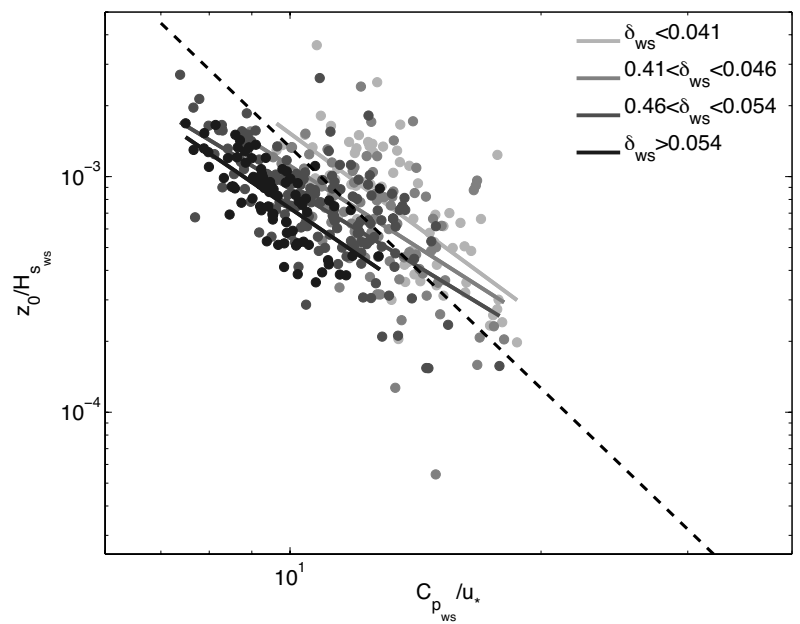

FIG. 7. - Dimensionless surface roughness as a function of the wind sea wave age. Colours denote different wind sea steepness, $\delta_{w s}$, ranges and lines are the logarithmic fit for different wind sea steepness ranges (solid) and the parameterization of Drennan et al. (2003) (dashed). impact on drag estimates from the IntOA experiment in low wind conditions (García-Nava et al. 2009). The effect of the direct interaction of swell with the air flow decreases rapidly with increasing wind speed (Pan et al. 2005). Therefore, in the following we restrict the analysis of field data to high winds and discuss the parameterization of the effect of direct interaction of swell and wind on the drag coefficient in the next section. While most data considered in this section correspond to wind sea-dominated conditions $(66.4 \%)$, there is an ubiquitous presence of swell and data can be regarded as mixed sea conditions.

In Figure 7 dimensionless roughness is plotted as a function of wind sea wave age. Although there is a slight tendency of roughness to decrease with increasing wave age, the data are scattered and no clear relation can be noticed. However, the tendency seems clearer if dimensionless roughness is categorized with wind sea wave steepness, $\delta_{w s}$. Also notice that the roughness of the steepest waves (darker circles) is lower than that estimated for pure wind seas using the relationship of Drennan et al. (2003) (dashed line), while less steep waves seem to be rougher than is expressed by the pure wind sea relationship. The steepest waves correspond to the highest winds in which the reduction of $z_{0}$ due to swell is an important process; as wind speed decreases (less steep waves) the reduction in $z_{0}$ is smaller and can be overcome by the direct contribution of momentum from swell to the atmosphere (García-Nava et al. 2009). The effect of swell on wind sea wave steepness can be observed in Figure 8 as the progressive decreasing of $H s_{w s}$ as a function of $\lambda_{p_{w s}}$ as the importance of swell parameter, $\zeta=E_{s} / E_{w s}$, increases. For a given wave length, as swell becomes greater, significant wave height and hence steepness decrease.

Figure 9 shows the observed dimensionless roughness as a function of wave steepness. The observed $z_{0}$ values are much more scattered than those in terms of the wind sea wave age and are consistently lower

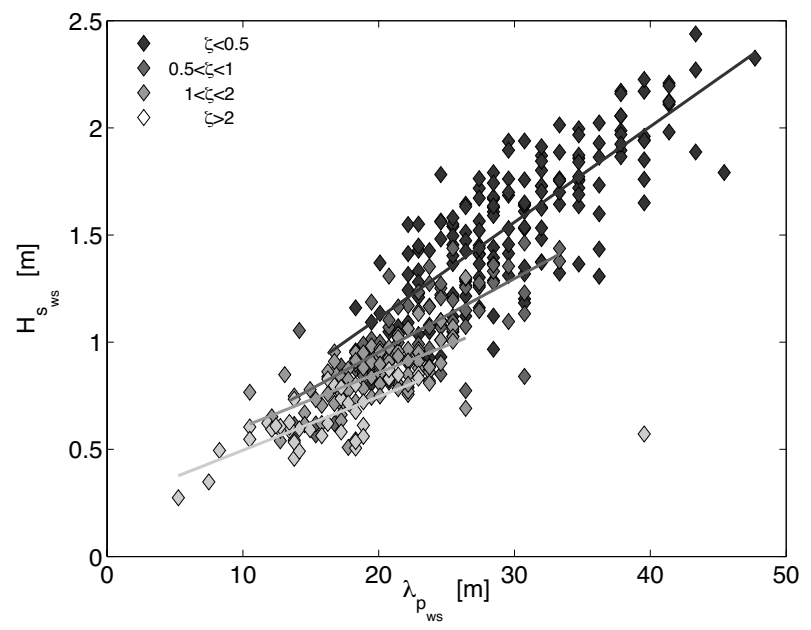

FIG. 8. - Wind sea significant wave height, $H_{\text {sis }}$, as a function of wind sea wave length, $\lambda_{w s}$. Colours denote different swell importance parameters, $\zeta$; ranges and lines are the linear fit in each range. 


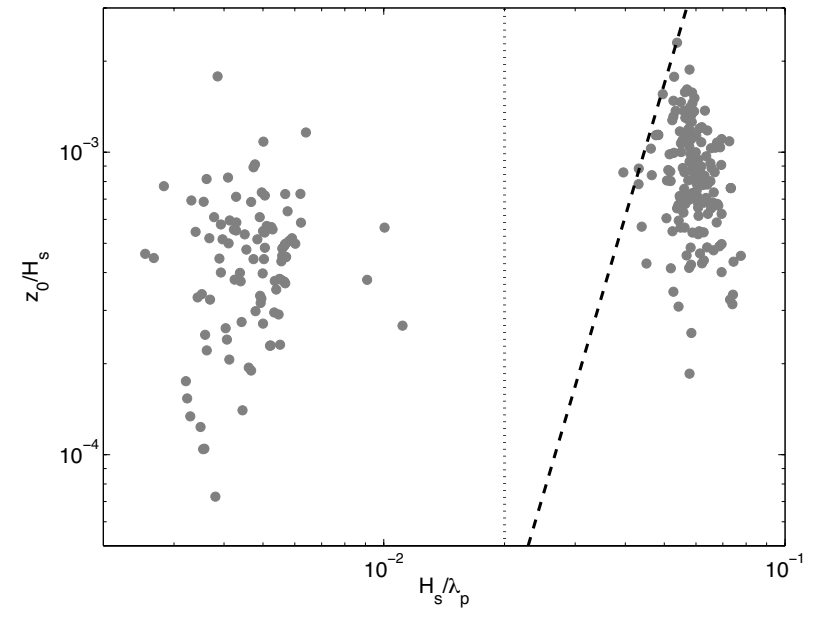

FIG. 9. - Dimensionless surface roughness as a function of the wave steepness. Lines are the parameterization of Taylor and Yelland (2001) (dashed) and the limit suggested by Drennan et al. (2005) (dotted).

that those predicted by the relationship of Taylor and Yelland (2001) (dashed line). In the figure, the limit proposed by Drennan et al. (2005) for the applicability of this formula is shown by the dotted line. For the IntOA data this limit clearly distinguishes the SD conditions from the WSD conditions because for the SD conditions the peak frequency corresponds to that of the swell, so wave steepness is much smaller.

In accordance with the results of Drennan et al. (2005), the wave steepness formula of Taylor and Yelland (2001) should perform better than the wave age formula of Drennan et al. (2003) for mixed sea conditions. However, the wave age formula seems to work better although none of these parameterizations is capable of predicting the $C_{D}$ observed during the IntOA experiment correctly and the modelled values greatly exceed the observations (Figs. 5c and 5d). In particular, the steepness formula represents the worst outcome of all $C_{D}$ models tested with a correlation coefficient, $R$, with observed data as low as 0.06 . In contrast, wave age formula has a high $R$ but the error in $C_{D}$ prediction is as high as the error computed for the steepness formula (Table 2).

From the analysis of the results presented in Figure 7 , it follows that $z_{0}$ should be parameterized in terms of both wave age and steepness. A combination of (11) and (12) can be arranged as

$$
z_{0} / H_{s_{w s}}=A_{n}\left(\frac{c_{p_{w s}}}{u_{*}}\right)^{B_{1 n}}\left(\frac{H_{s_{w s}}}{\lambda_{p_{w s}}}\right)^{B_{2 n}},
$$

where all wave characteristics refer to wind sea properties.

Based on the IntOA data, we obtained $A_{n}=0.0235$, $B_{1 n}=-2.224$ and $B_{2 n}=-1.09$. Figure 5e shows a comparison between the observed $C_{D}$ and that computed with (13). The improvement in $C_{D}$ prediction is readily apparent (Table 2). Note that all wave parameters included in (13) are from the wind sea and so, the effect of swell on wind stress is implicitly included through the dependence of the wind sea properties on swell (see e.g. Fig. 8).

Another approach to include a sea state dependence on the parameterization of wind stress is to consider $C_{D}$ as a function of the dimensionless frequency $\omega_{*}$, as (Hwang 2004)

$$
C_{D_{\lambda / 2}}=A_{c} \omega_{*}{ }^{B c}
$$

where the height $z=\lambda / 2$ is used to reduce the uncertainty introduced by the use of the arbitrary $10-\mathrm{m}$ reference elevation and because $U_{\lambda / 2}$ can be regarded as a proper free stream velocity (see discussion in Section $3 \mathrm{~b}$ of Hwang et al. 2011). For wind seas, $A_{c}$ and $B_{c}$ are constants if $\omega_{*}=\omega_{p} u_{*} / g$, where $\omega_{p}$ is the angular frequency at the wave spectral peak (Hwang 2004). Notice that for deep-water waves $\omega_{p} u_{*} / g=u_{*} / c_{p}$, so (14) is an analogous form of (11). For mixed seas Hwang et al. (2011) proposed the use of a characteristic wave frequency $\omega_{p M}$ defined from the wave momentum spectrum as

$$
\omega_{p M}=\frac{\int S(\omega) d \omega}{\int S(\omega) \omega^{-1} d \omega},
$$

where $S(\omega)$ is the wave frequency spectrum instead of $\omega_{p}$ and expressed $A_{c}$ and $B_{c}$ as functions of the swell index $I_{s}=\omega_{p M} / \omega_{p}$. In Figure $5 \mathrm{f}$ it can be seen that the $C_{D}$ estimated with this swell-dependent parameterization reproduces very well the observed $C_{D}$ and the overall performance is only slightly worse than that of (13) (Table 2).

\section{The effect of swell on drag at low wind speeds}

At low winds it is expected that the greatest effect of swell on momentum flux will be brought by the direct interaction of the swell waves with the air flow (Donelan and Dobson 2001. From their analysis, García-Nava et al. (2009) concluded that the presence of swell caused the relatively high $C_{D}$ values observed in low winds during the IntOA experiment (Fig. 4).

The total wind stress can be regarded as a sum of the turbulent stress, $\tau_{t}$, the wave-related Reynolds stress, $\tau_{\eta}$, and the viscous stress, $\tau_{v}$. The viscous stress is only important in the very near vicinity of the surface, inside the viscous sublayer, while the waverelated stress is important within the wave-atmospheric boundary layer. The dynamic effects of waves decays exponentially with distance from the surface and with the wavelength, as $\exp (-2 \pi z / \lambda)$, and so at a certain distance from the surface the greater effect of waves on the air flow will be caused by the longer waves. In low wind conditions and at common measuring heights it is expected that $\tau_{\eta}$ will be related predominantly to the swell, so $\tau=\tau_{t}+\tau_{s}$, where $\tau_{s}$ is the swell-related stress and we have neglected the viscous stress. Equivalently, the drag coefficient can be decomposed as $C_{D}=C_{D_{t}}+C_{D_{s}}$. The swell-related drag coefficient, $C_{D_{s}}$, decays with 
increasing wind speed and depends on swell characteristics. Recently, Pan et al. (2005) showed that $C_{D_{s}}$ depends on swell steepness and on the ratio between the swell phase speed and the wind speed, and proposed a parameterization accordingly. Here we computed the swell-related stress from the part of the wind velocity spectrum which is coherent with the waves $S_{\tilde{u} \tilde{u}}$ as described by Veron et al. (2008)

$$
\frac{\tau_{s}}{\rho}=\int_{f_{s}}\left(S_{\tilde{u} \tilde{u}} S_{\tilde{w} \tilde{w}}\right)^{1 / 2} \cos \left(\Phi_{w \eta}-\Phi_{u \eta}\right) d f,
$$

where $f_{s}$ indicates that integration is made over swell frequencies, $\tilde{\mathbf{u}}$ is the wind velocity coherent with the waves,

$$
\begin{aligned}
S_{\tilde{\mathrm{u}}} & =S_{\mathrm{uu}} \times C_{u \eta}^{2}, \\
S_{\tilde{\mathrm{w}} \tilde{\mathrm{w}}} & =S_{w w} \times C_{w \eta}^{2},
\end{aligned}
$$

$S_{\mathbf{u u}}$ is the wind velocity spectrum, and $\Phi_{\mathbf{u} \eta}$ and $C_{\mathbf{u} \eta}$ are the phase and coherence between the wind velocity and the sea surface height $\eta$. Then $C_{D_{s}}$ was computed as

$$
C_{D s}=\frac{\tau_{s}}{\rho U_{10}^{2}}
$$

In general, there is a good agreement between $C_{D_{s}}$ computed with (18) and that computed from the parameterization of Pan et al. (2005) (Fig. 10). In both cases $C_{D_{s}}$ exhibits the expected decay with increasing wind speed and computed values are of such magnitude that they can account for the high values of $C_{D}$ observed during the IntOA experiment in low wind conditions.

\section{CONCLUSIONS}

The presence of swell modifies the momentum flux through at least two different mechanisms: 1) the swell releases or accepts momentum from air flow and 2) the swell modifies the wind-sea-associated roughness, which in turns modifies the momentum transfer between the atmosphere and the ocean (Donelan and Dobson 2001). In mixed seas with strong swell the first mechanism is important in low wind conditions (e.g. Donelan et al. 1997, Drennan et al. 1999, Pan et al. 2005), while the second is believed to have a greater impact in high wind conditions whenever underdeveloped wind waves coexist with strong swell (GarcíaNava et al. 2009).

Given the influence of swell on wind stress, the need to include the sea-state dependence of $C_{D}$ or $z_{0}$ on the corresponding parameterizations is obvious. Here we have tested several parameterizations with the IntOA data set and show that the best results regarding $C_{D}$ prediction are obtained when $z_{0}$ is parameterized in terms of both the wind sea wave age and steepness, or when the similarity relationship proposed by Hwang et al. (2011) is used. It should be noted that the coef-

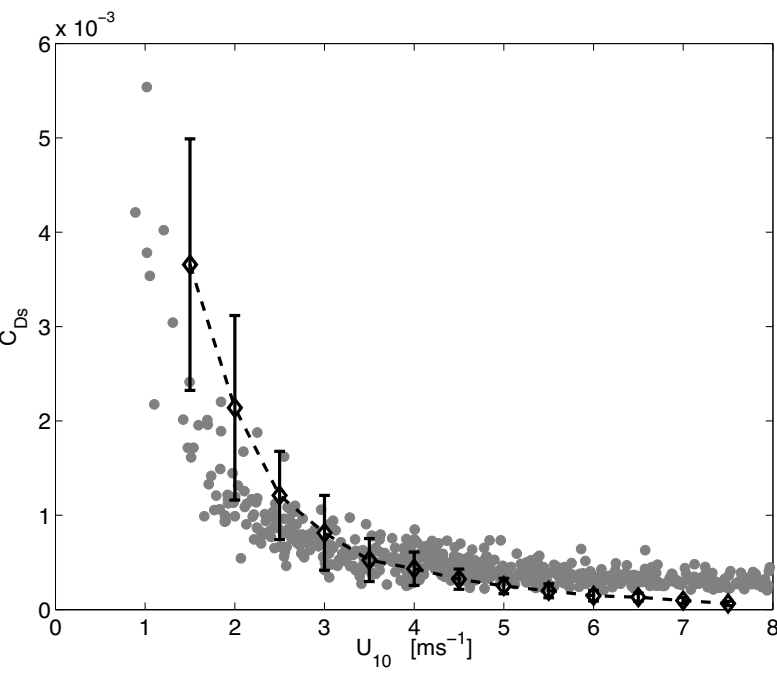

FIG. 10. - Swell-related drag coefficient $\left(C_{D_{s}}\right)$ computed from the wind velocity spectrum coherent with the waves (circles) as a function of wind speed. Diamonds are the mean $C_{D s}$ computed from the relationship of Pan et al. (2005) for wind increments of $1 \mathrm{~m} \mathrm{~s}^{-1}$ and error bars are two standard deviations.

ficients and exponents used in both parameterizations, equation (13) and that of Hwang et al. (2011), were obtained by fitting the IntOA data set. Therefore, a further validation of these formulas should include several data sets and is being considered as a next step.

In (13) the effect of swell on $C_{D}$ is included implicitly in the dependence of wind sea parameters on the presence of swell, while the parameterization of Hwang et al. (2011) explicitly includes the dependence of $C_{D}$ on swell by using the characteristic wave frequency (see Eq. 15) to compute $C_{D_{12}}$. A point worth noting is that the exponent $B_{2 n}=-1.09$ of (13) implies that the dependence of dimensionless roughness on wave steepness is almost linear. If we set $B_{2 n}=-1$ then (13) can be rewritten as

$$
\frac{z_{0}}{\lambda}=A_{n}\left(\frac{c_{p}}{u_{*}}\right)^{B_{1 n}} \text {. }
$$

Furthermore, using $z=\lambda / 2$ on (3) gives

$$
C_{D_{\lambda / 2}}=-\kappa^{2} \ln ^{2}\left(2 \frac{z_{0}}{\lambda}\right) \text {. }
$$

From (19) and (20) it can be seen that the parameterization described by (13) and the parameterization of $C_{D_{\lambda / 2}}$ of Hwang et al. (2011) are somewhat analogous, and this suggests that scaling $z_{0}$ with $\lambda$ could be a better alternative than the commonly used scaling with $H_{s}$.

The observed swell-related drag coefficient is well represented by the parameterization of Pan et al. (2005) (Fig. 10). A computation of the total $C_{D}$ obtained by adding $C_{D_{s}}$ and $C_{D_{t}}$, where $C_{D_{s}}$ is approximated with the relationship of Pan et al. (2005) and $C_{D_{t}}$ is computed with (13), is a good approximation to the observed $C_{D}$ and reflects fairly well the general trend of $C_{D}$ as a function of wind speed, although the individual val- 
ues of $C_{D}$ in low winds are not an exact match. The effect of swell on increasing $C_{D}$ in low winds can be represented by the inclusion of $C_{D}$ computed with the parameterization of Pan et al. (2005).

\section{ACKNOWLEDGEMENTS}

Suggestions and comments from two anonymous reviewers enriched this work. We gratefully acknowledge support by CONACYT (projects: REDESClim, CONACYT 62520, CONACYT-SEP 85108, and SEP-2003-C02-44718) and the Office of Naval Research (Naval Research Laboratory Program Element $61153 N)$. HGN gratefully acknowledge financial support from DOF/CICESE.

\section{REFERENCES}

Charnock H. 1955. Wind stress on water surface. Q. J. R. Meteorol. Soc. 81: 639-640.

Donelan M.A., 1990. Air-sea interaction. In: LeMehaute B., Hanes D.M. (eds.), The Sea, vol. 9, Ocean Engineering Science. John Wiley \& Sons Inc., pp. 239-292.

Donelan M.A., Dobson F.W. 2001. The influence of swell on the drag. In: Jones I.S.F., Toba Y. (eds.), Wind Stress Over The Ocean. Cambridge University Press, New York, N.Y., pp. 181-190.

Donelan M.A., Drennan W.M., Katsaros K.B. 1997. The air-sea momentum flux in conditions of wind sea and swell. J. Phys. Oceanogr. 27: 2087-2099.

Drennan W.M. 2006. On parameterisations of air-sea fluxes. In: Perrie W. (ed.), Atmosphere-Ocean Interactions, Vol. 2. WIT Press, pp. 1-34.

Drennan W.M., Kahma K.K., Donelan M.A. 1999. On momentum flux and velocity spectra over waves. Bound.-Lay. Meteorol. 92: 489-513.

Drennan W.M., Graber H.C., Hauser D., Quentin C. 2003. On the wave age dependence of wind stress over pure wind seas. $J$. Geophys. Res. 108: 8062

Drennan W.M., Taylor P.K., Yelland M.J. 2005. Parametrizing the sea surface roughness. J. Phys. Oceanogr. 35: 835-848.

Foreman R.J., Emeis S. 2010. Revisiting the definition of the drag coefficient in the marine atmospheric boundary layer. J. Phys. Oceanogr. 40: 2325-2332.

García-Nava H., Ocampo-Torres F. J., Osuna P., Donelan M.A. 2009. Wind stress in the presence of swell under moderate to strong wind conditions. J. Geophys. Res. 114: C12008.

Geernaert G.L. 1999. Air-sea exchange: Physics, chemistry and dynamics. Kluwer Academic, 578 pp.

Graber H.C., Terray E.A., Donelan M.A., Drennan W.M., Leer J.C.V., Peters D.B. 2000. ASIS-A New Air-Sea Interaction Spar Buoy: Design and Performance at Sea. J. Atmos. Oceanic. Technol. 17: 708-720.

Guan C., Xie, L. 2004. On the linear parameterization of drag coefficient over sea surface. J. Phys. Oceanogr. 34: 2847-2851.

Hara T., Belcher S.E. 2004. Wind profile and drag coefficient over mature ocean surface wave spectra. J. Phys. Oceanogr. 34: 2345-2358

Hwang P.A. 2004. Influence of wavelength on the parameterization of drag coefficient and surface roughness. J. Oceanogr. 60: 835-841.

Hwang P.A., García-Nava H., Ocampo-Torres F.J. 2011. Dimensionally consistent similarity relation of ocean surface friction coefficient in mixed seas. J. Phys. Oceanogr. 41: 1227-1238.

Jones I.S.F., Toba Y. 2001. Wind stress over the ocean. Cambridge University Press, $303 \mathrm{pp}$.

Komen G. J., Janssen P.A.E.M., Makin V., Oost W. 1998. On the sea state dependence of the Charnock parameter. Global Atmos. Ocean Syst. 5: 367-388.

Large W.G., Pond S. 1981. Open ocean momentum flux measurements in moderate to strong winds. J. Phys. Oceanogr. 11: 324-336.

Moon I., Ginis I., Hara T. 2004. Effect of surface waves on Charnock coefficient under tropical cyclones. Geophys. Res. Lett. 31: L20302.

Ocampo-Torres F.J., García-Nava H., Durazo R., Osuna P., Díaz Méndez G.M., Graber H.C. 2011. The IntOA experiment: A study of ocean-atmosphere interactions under moderate to strong offshore winds and opposing swell conditions in the Gulf of Tehuantepec, Mexico. Bound.-Lay. Meteorol. 138: 433-451.

Pan J., Wang D.W., Hwang P.A. 2005. A study of wave effects on wind stress over the ocean in a fetch-limited case. J. Geophys. Res. 110: C02020.

Romero R., Zavala J., Gallegos A., O'Brien J.J. 2003. Isthmus of Tehuantepec wind climatology and ENSO signal. J. Climate 16: 2628-2639.

Smith S.D. 1980. Wind stress and heat flux over the ocean in gale force winds. J. Phys. Oceanogr. 10: 709-726.

Sreenivasan K.R., Chambers S.J., Antonia R.A. 1978. Accuracy of moments of velocity and scalar fluctuations in the atmospheric surface layer. Bound.-Lay. Meteorol. 14: 341-359.

Taylor P.K., Yelland, M.J. 2001. The dependence of sea surface roughness on the height and steepness of the waves. J. Phys. Oceanogr. 31: 572-590.

Veron F., Melville W.K., Lenain L. 2008. Wave-coherent air-sea heat flux. J. Phys. Oceanogr. 38: 788-802.

Yelland M., Taylor P.K. 1996. Wind stress measurements form the open ocean. J. Phys. Oceanogr. 26: 541-555.

Received March 31, 2011. Accepted November 9, 2011.

Published online August 6, 2012. 